\title{
Rock slope stability problems in Gold Coast area, Australia
}

Shokouhi Ali, Gratchev Ivan, Charrismanagara Arry

Griffith University - Gold Coast campus - Australia

\begin{abstract}
The Tamborine Mountain area of the Gold Coast, Australia often faces rock slope failures during rainy seasons. To have a better understanding of the factors that may affect the slope stability, several rock slope sites have been examined in detail to assess the effect of discontinuities formed in the rock masses, and degree of weathering of the rocks on the overall stability of slopes. Different methods of slope stability analysis such as kinematic approach and slope mass rating, were applied to investigate the potential failure mode and predict the behavior of rock slopes in the future. This paper will present results of this work and make comparisons between different methods of rock slope stability analysis. Keywords: slope stability, discontinuity, kinematic approach, SMR
\end{abstract}

\section{INTRODUCTION}

Tamborine Mountain, located in south of Brisbane and inland from the Gold Coast, is a plateau formed on sub-horizontal basalt lavas of Tertiary age[1]. It is covered by forest. The basalt plateaux of southeast Queensland potentially has hazard of landsliding[1], and often faces rock slope failures during rainy seasons.

Many of residences in Tamborine Mountain are located near the rock slopes which have potential hazard of movement and instability. Failure of these rock slopes can lead to damaging results and will have a deep economic and social impact on the society of this area. Also the slope failure can be very harmful for infrastructures located in Tamborine Mountain such as roads. Every year during the rainy seasons, many of access roads are closed by failed slopes.

The objective of this study is to investigate some cut slopes through the main roads and analyze them with using kinematic approach Slope Mass Rating (SMR) to identify the potential failure modes of them and to determine the condition of slopes located along roads.

The investigation field was located along Beaudesert Nerang Road, immediately south-east of the Beaudesert Nerang Road / Arunta Drive intersection, on the Gold Coast (Fig. 1). The approximate length of the existing cut slope is $200 \mathrm{~m}$ and with the height of approximately $7 \mathrm{~m}$. (Fig.2)

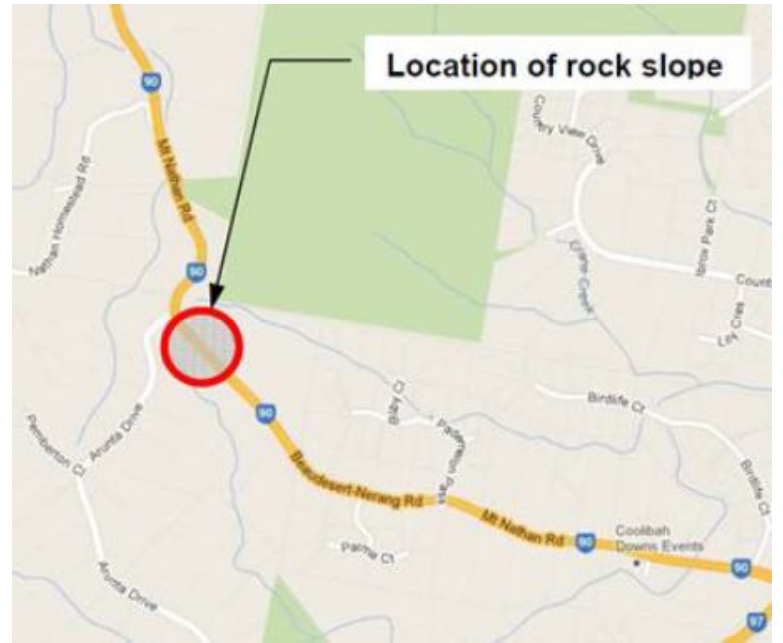

Figure 1 - Location on investigated slopes

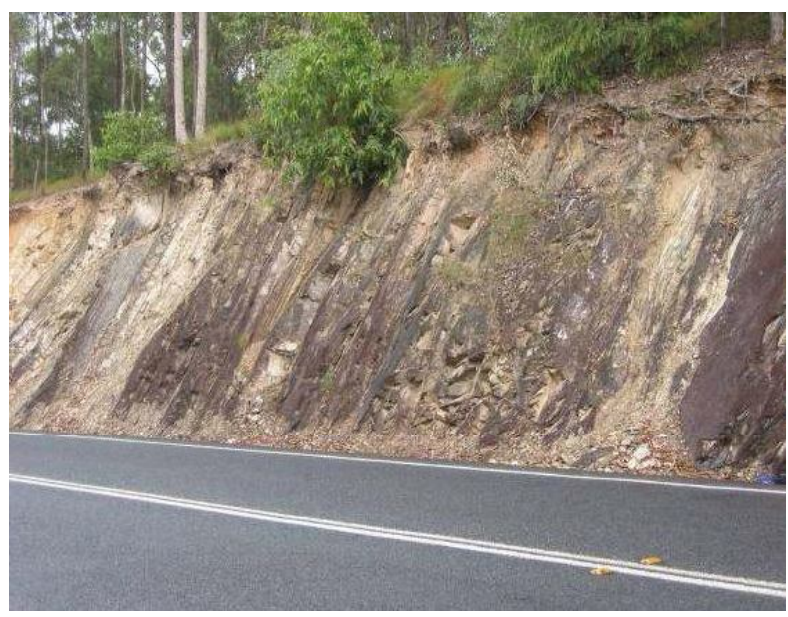

Figure 2 - One of investigated slopes 


\section{Geology and landslides types}

The regional geological structure of the Tamborine Mountain and detailed geology of the basalt lavas forming the plateau surface area have been described by Willmott[1], Cranfield et al [2], and Green [3].

The investigation field was located on the eastern part of Tamborine Mountain and made of metasediments of Neranleigh-Fernvale Beds. Based on investigation performed by [1], this sequence of mainly sedimentary rocks was deposited in Devonian to Carboniferous times. These rocks have been deformed, indurated and slightly metamorphosed, probably in the Carboniferous; they now can be termed metasediments. The main rock types present are argillite (derived from siltstone and shale), greywacke dark sandstone with abundant rock fragments), quartzite (derived from chert) and greenstone (metamorphosed submarine basalt lavas). Conglomerate horizons are known in a few areas. In some places, the argillite is sheared and has the appearance of phyllite.

In 1981 a slope stability investigation performed by [1], on Tamborine Mountain, his investigation showed that few landslides are known on the plateau surface of the mountain, but numerous slides, some very large, have occurred on the cliff lines and benches below, and on the fans of colluvial debris along the lower western flanks of the mountain. Based on his investigation, amongst different types of slope instability, four main types of landslides can occur in Tamborine mountain including: Rock falls, Debris flows, small rotational slides and complex multiple rotational slides.

\section{Field survey}

To assess the impacts of formed discontinuity and weathering on the rock slopes located in Tamborine Mountain, site investigations were performed in 2012 to collect the relevant and required data such as: Geometric properties of discontinuities such as: dip, dip direction, spacing, etc., compressive strength by using Schmitt hammer and types of rocks.

Three locations were selected along the rock slope located in the side of main road for these investigations.

The following data were collected:

Table I- Collected data

\begin{tabular}{|c|c|c|c|c|}
\hline \multicolumn{5}{|c|}{ Location 1 } \\
\hline Set \# & Dip & $\begin{array}{c}\text { Dip } \\
\text { direction }\end{array}$ & $\begin{array}{c}\text { Aperture } \\
(\mathbf{m m})\end{array}$ & $\begin{array}{c}\text { Compressive } \\
\text { Strength of } \\
\text { rocks (Mpa) }\end{array}$ \\
\hline 1 & 55 & 220 & 0.5 & 27 \\
\hline 2 & 50 & 135 & 0.5 & 27 \\
\hline 3 & 55 & 50 & 2 & 27 \\
\hline \multicolumn{5}{|c|}{ Location 2 } \\
\hline Set \# & Dip & $\begin{array}{c}\text { Dip } \\
\text { direction }\end{array}$ & $\begin{array}{c}\text { Aperture } \\
\text { (mm) }\end{array}$ & $\begin{array}{c}\text { Compressive } \\
\text { Strength of } \\
\text { rocks (Mpa) }\end{array}$ \\
\hline 1 & 61 & 70 & $1-2$ & 40 \\
\hline 2 & 73 & 170 & $1-2$ & 27 \\
\hline
\end{tabular}

\begin{tabular}{|c|c|c|c|c|}
\hline \multicolumn{5}{|c|}{ Location 3 } \\
\hline Set \# & Dip & $\begin{array}{c}\text { Dip } \\
\text { direction }\end{array}$ & $\begin{array}{c}\text { Aperture } \\
(\mathbf{m m})\end{array}$ & $\begin{array}{c}\text { Compressive } \\
\text { Strength of } \\
\text { rocks (Mpa) }\end{array}$ \\
\hline 1 & 40 & 40 & 0.5 & 45 \\
\hline 2 & 73 & 170 & $1-2$ & 27 \\
\hline 3 & 25 & 240 & $3-5$ & 27 \\
\hline
\end{tabular}

\section{Data analyses}

The collected data were analyzed by Dips computer software to identify the potential failure modes of the investigated slopes. The results from kinematic analysis indicate that at location 1 , there is only one potential failure mode. Planar sliding is the most likely failure mode that may occur at this location (Fig.3). As can be seen in Fig3 some of the discontinuities are located in gray shade that shows the potential planar sliding area. Toppling and wedge failure analyses show, there are no toppling and wedge potential failure at location 1 .

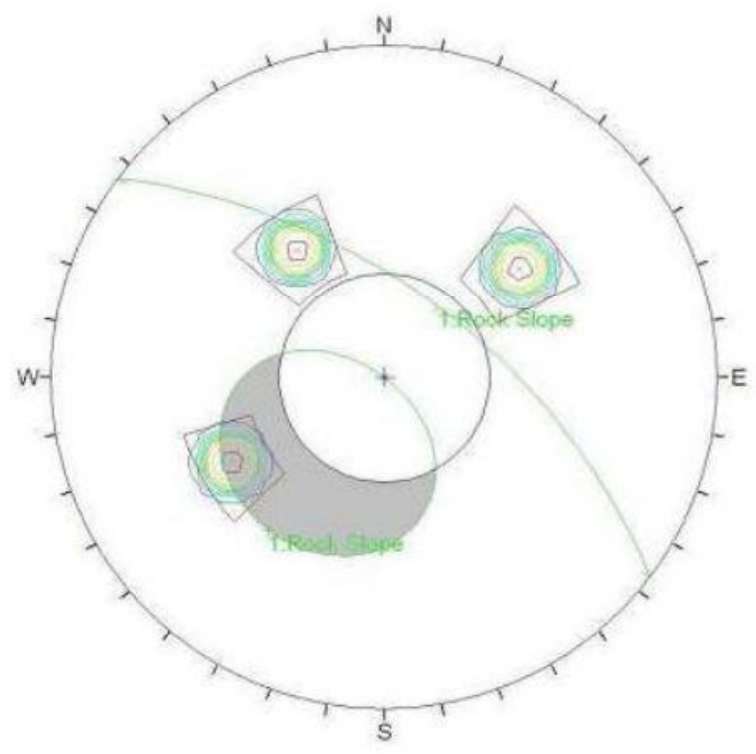

Figure 3 - Planar sliding of location 1

In location 2 , the results produced by kinematic analysis suggest that there may be a potential toppling failure (Fig.4). In Fig.4, a part of the contour lines fall within the toppling failure zone that indicates the potential toppling failure. 


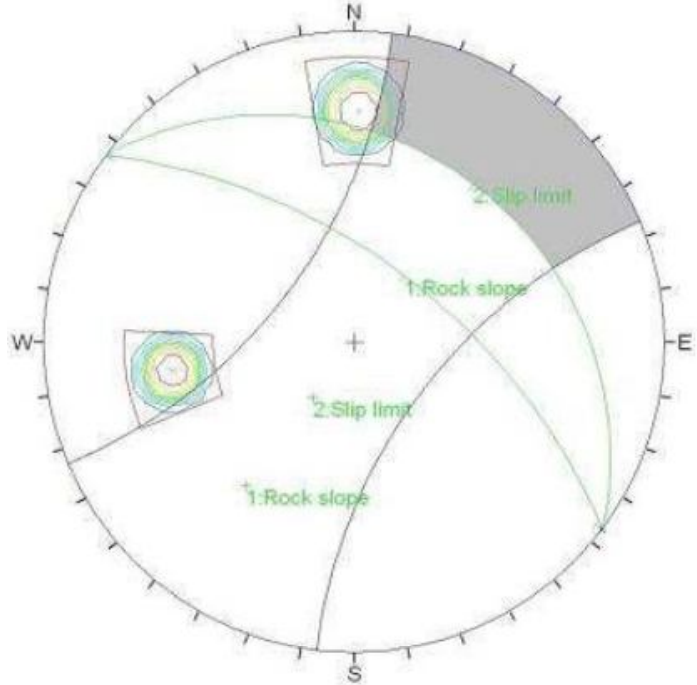

Figure 4 - Toppling failure of location 2

The results of kinematic analysis show that the rock slope at location 3 has two potential failure modes, planar sliding and wedge sliding. In Fig. 5, the discontinuity set \#3 falls within the failure zone (grey shaded area) for planar sliding analysis. This means that planar sliding may occur along this failure plane.

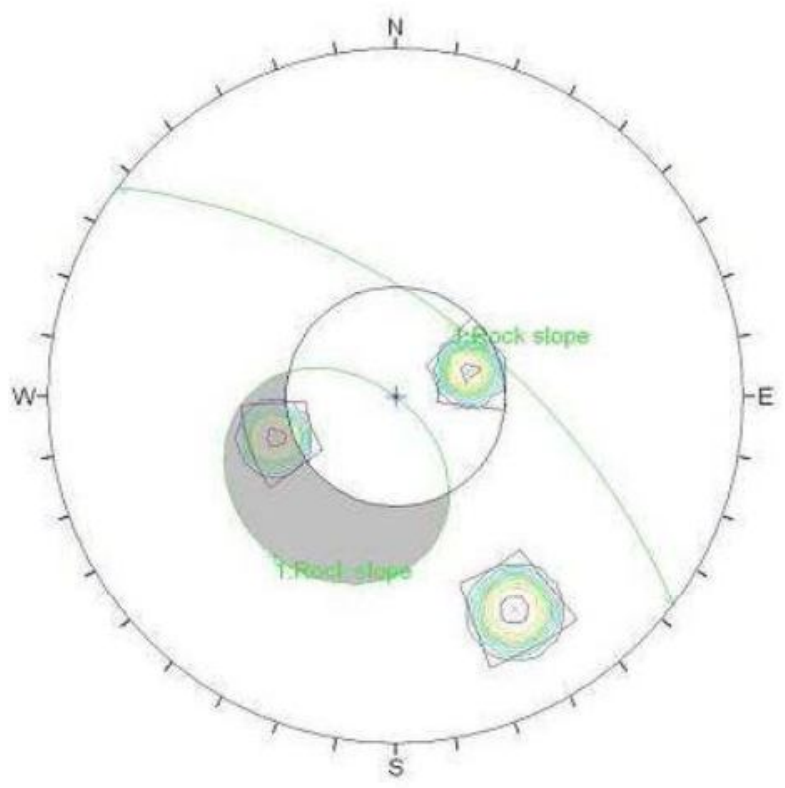

Figure 5 - Toppling failure for location 3

Fig.6 shows that there is a mean joint set orientation intersection (shown by black dots) that falls within the wedge failure zone (grey shaded area). This indicates that a wedge failure may potentially occur at location 3 .

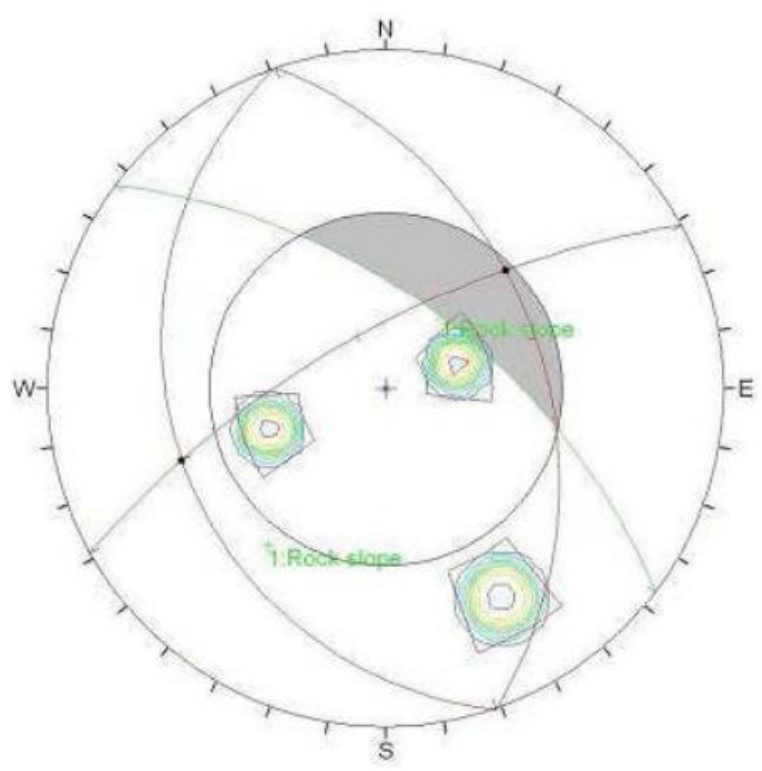

Figure 6 - Wedge failure of location 3

Besides the kinematic analysis a SMR (Slope Mass Rating) analysis was also conducted to assess the slopes. Following table indicates the results of SMR analyses.

Table II- SMR results

\begin{tabular}{|c|c|c|}
\hline Location & SMR & Slope Mass Class \\
\hline 1 & 40 & IV, Poor \\
\hline 2 & 83 & I, Very good \\
\hline 3 & 14 & V, Very poor \\
\hline
\end{tabular}

The results from SMR analyses consistently show that location 2 has the best rock mass condition out of the three locations, followed by location 1, and location 3 has the worst. These results reflect the evidence that there was a significant recent rock fall at location 3 . At location 1 , the rock fall was deemed to be minor, however, small fragments of rock blocks were found along the toe of the rock slope.

\section{Concluding remarks}

The results of kinematic analyses show that at location 1 , the rock is unstable under current conditions. However, in an event of a rock slope failure, it will only be a minor one. At location 2 of the rock slope, the geometry condition and high strength of rock duo to less weathering lead to a better condition than the other two locations. The SMR analysis result of this location indicates that the rock slope is class ' $\mathrm{I}$ ', which means that the slope is completely stable. However, the results from kinematic analysis suggest that there may be a possibility that the rock slope at this location will fail in toppling.

All the analysis done on the rock slope at location 3, point out that this section of the slope is the least stable out of the three.

The following table illustrates the comparison of results 
between these two different approaches (Kinematic and SMR).

Table III- Comparison of results

\begin{tabular}{|c|c|c|c|c|c|}
\hline \multirow{2}{*}{ Set \# } & \multicolumn{3}{|c|}{ SMR } & \multicolumn{3}{c|}{ Kinematic approach } \\
\cline { 2 - 6 } & SMR & Grade & Toppling & Planar & Wedge \\
\hline 1 & 40 & IV, Poor & - & + & - \\
\hline 2 & 83 & I, Very good & + & - & - \\
\hline 3 & 14 & V, Very poor & + & - & + \\
\hline
\end{tabular}

It can be deducted from the above table that, the results of both analyses have a good concordance with each other and in term of stability both show same outcomes.

\section{REFERENCES}

[1] Willmott, W.F., Slope Stability and Its Constraints On Closer Settlement On Tamborine Mountain, Southeast Queenslan, 1981, Department Of Mines Geological Survey Of Qucensland.

[2] CRANFIE, L.C., SCHWARZBOCK. H., \& DAY, R.W., Geology of the Ipswich and Brisbane 1:250 000 Sheet areas, in Geological Survey of Queensland, Report 95,1976.

[3] GREEN. D.C.. The volcanic rocks of Mt Tamborine, South-East Queensland., in Department of Geology1964, University of Queensland. 